\title{
Approximation and the coercion of gradable predicates
}

Erin Zaroukian, zaroukian@ cogsci.jhu.edu

\section{Puzzle}

Approximators can appear in with numerals in constructions like (1) and (2).

(1) John served \{approximately/about 50 sandwiches.

(2) What John served was \{approximately/about\} 50 sandwiches.

Approximators are more restricted, however, in their ability to appear with coerced-scalar NPs like beef stroganoff in (3) and (4).

(3) John served \{??approximately/??about $\}$ beef stroganoff.

(4) What John served was \{approximately/??about\} beef stroganoff.

The goal of this paper is to explain the asymmetries in (1)-(4). First, I address the question of why numerals pattern differently from coerced-scalar NPs, as shown in (1) and (2) v. (3) and (4). This, I propose, is a matter of semantic argument structure. Second, I address the question of why approximately and about pattern identically with numerals but differently with coerced-scalar NPs. I propose that this is due to about's inability to coerce scalars readings from NPs.

\section{Modified numerals}

I will assume an analysis of modified numerals along the lines of Hackl (2000). He proposes that bare numerals like 50 combine with the phonologically-null degree function many, given in (5), and compose as in (6).

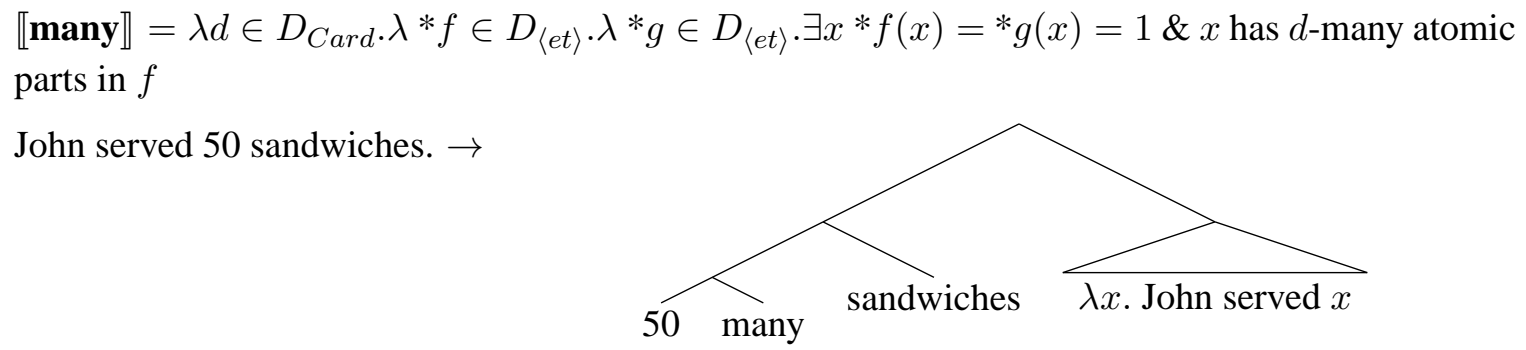

Numerals can also combine with degree modifiers (e.g. -er than $+n+$ many $=$ more than $n$ ), which compose as in (7).

(7) John served more than 50 sandwiches. $\rightarrow$

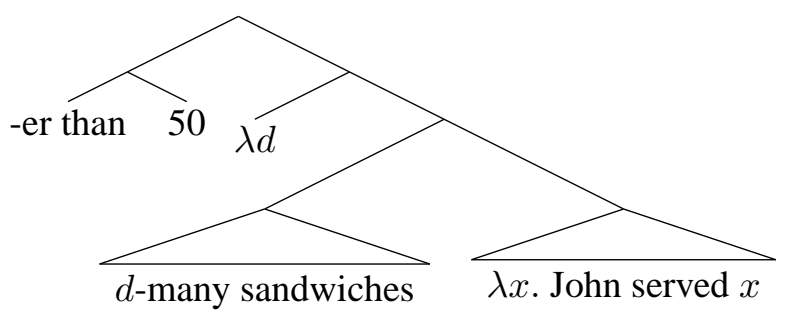


Hackl suggests treating exactly as a degree modifier, as shown in (8). In (9), exactly combines with the degree 50 and asserts that the quantity of atomic sandwiches that were served by John is 50 , and there is no degree greater than 50 that is true of that set.

$$
\llbracket \text { exactly } \mathbf{n} \rrbracket=\lambda D_{\langle d t\rangle} \cdot D(n)=1 \& \neg \exists d[d>n \& D(d)=1]
$$

John served exactly 50 sandwiches. $\rightarrow$

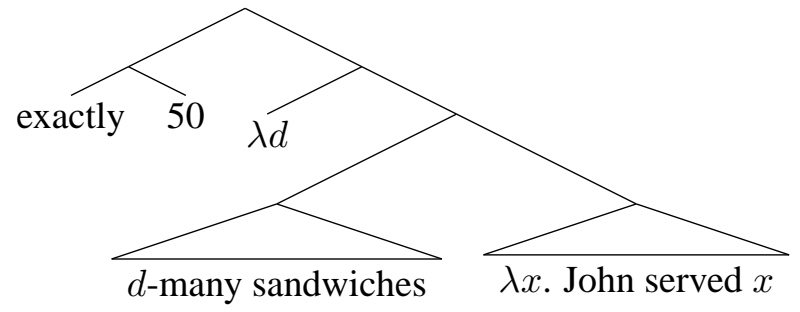

This analysis can easily be extended to approximately, as shown in (10). Here I treat approximately as a degree modifier which feeds many a degree that falls within some contextually-determined distance $\sigma$ of $n$.

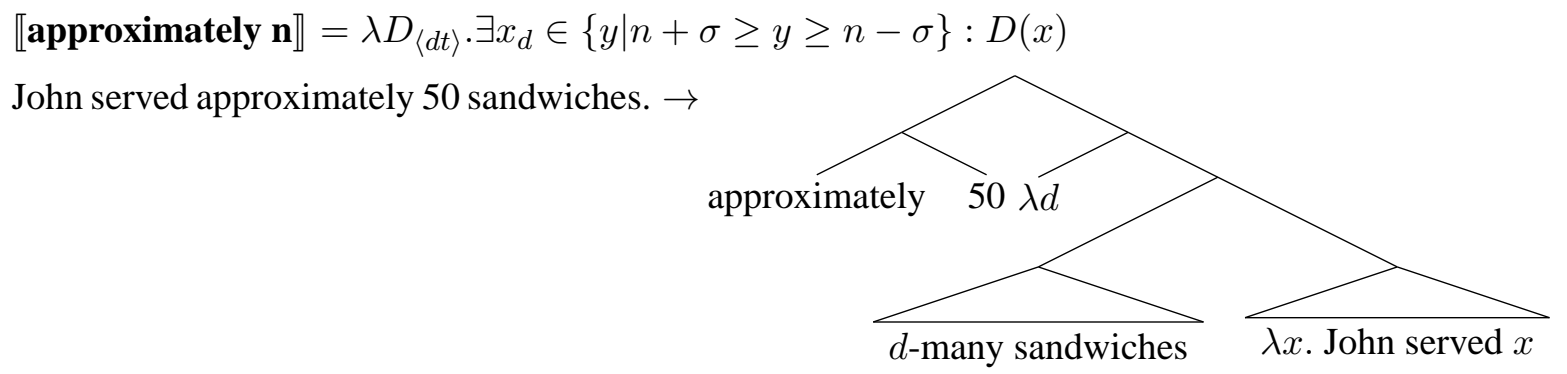

Now we can see how (1)-(2) fit into this framework, but more work is required to accommodate coerced scalars like beef stroganoff above.

I treat coerced scalars as denoting degrees; in (3)-(4), beef stroganoff will correspond to a degree on some scale representing beef-stroganoff-ness. We cannot use many with these constructions as it requires plural predicates and counting over atomic parts, so instead I will assume another phonologically-null degree function much.

$\llbracket \mathbf{m u c h} \rrbracket=\lambda d \in D_{d} \cdot \lambda f \in D_{\langle e t\rangle} \cdot \lambda g \in D_{\langle e t\rangle} \cdot \exists x f(x)=g(x)=1 \& x$ falls at $d$ on the relevant scale in $f$

\section{Approximately+NP}

With our compositional machinery in place, we will first address the question of why coercedscalar NPs pattern different from numerals, as shown in (1) and (2) v. (3) and (4).

In (3), much takes as arguments beef stroganoff (type $d$ (egree)) and $[\lambda x$. John served $x]$ (type $\langle e t\rangle$ ), but is still missing an argument of type $\langle e t\rangle$ and is therefore unacceptable. The sentence in (3) is is given again below, where the (missing) arguments of much are underlined. The composition is given in (13), with an X standing in place of much's missing argument.

(3) ??John served approximately beef stroganoff much 
(13)

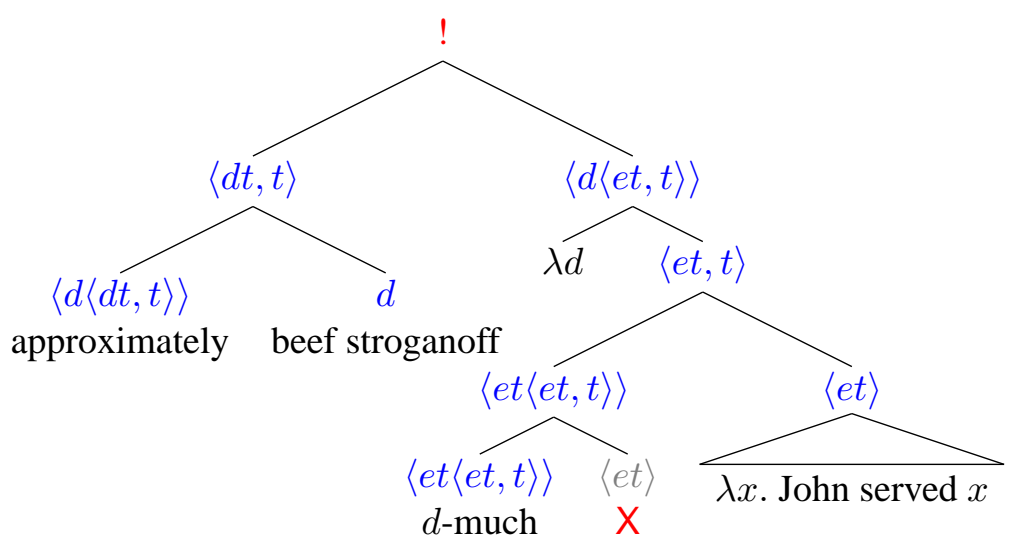

Additional support for missing $\langle e t\rangle$ argument in (3) can be seen with coerced scalar adjectives. In (14) the sentence is acceptable when an additional NP argument ( $\langle e t\rangle$, e.g. answer) is present. $\underline{\text { John gave an approximately-correct-much answer. }}$

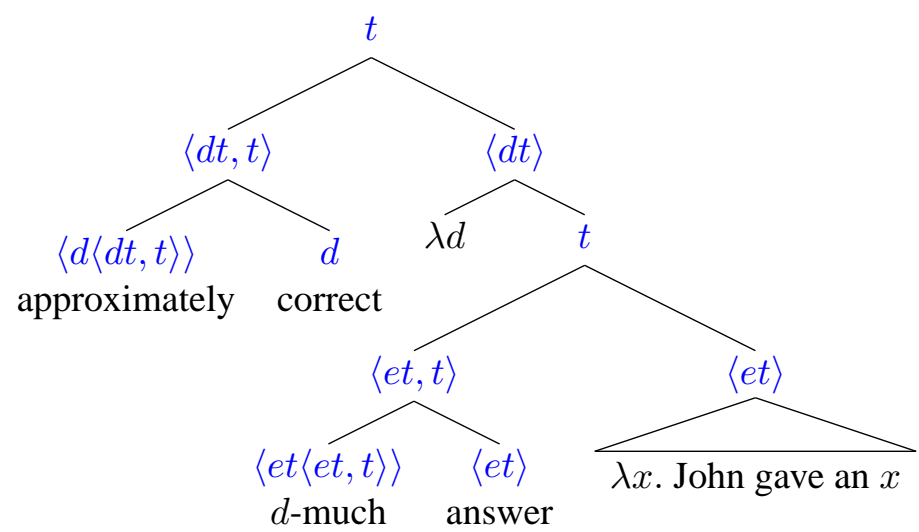

Given this explanation for the unacceptability of (3), however, the acceptability of (4) becomes mysterious: it too seems to be missing an argument of type $\langle e t\rangle$.

(4) What John served was approximately beef stroganoff much

Copular constructions appear to be a special case. Hackl suggests that they do they not require the item in post-copula position to be $\langle e t\rangle$ (it appears to be $\langle e t\langle e t, t\rangle\rangle$ in (16)).

The sandwiches were many.

However, it also appears that these post-copular items never become saturated. This may be circumvented by a copula-specific type shift a la Partee (2008) that would saturate one of many/much's arguments. Thus, the copula-specific type can explain the felicity of (4).

In sum, I treat approximately is a Hackl-style degree modifier. It appears with many/much, which requires two arguments of type $\langle e t\rangle$ unless it is in a copular construction. Since (1) does and (3) does not provide two $\langle e t\rangle$ arguments, (1) is and (3) is not acceptable. 


\section{Approximately v. about}

Now we have seen why approximately is good in (4) but not (3), and in this section I address the question of why is about acceptable in (1) and (2) but not (3) and (4). I propose that unlike approximately, about does not coerce scalar readings from nouns. Therefore, about cannot combine with non-inherently-scalar terms like beef stroganoff (similar behavior can be seen with other prepositions like around and near). This could be related to the availability of non-scalar meanings for about, as demonstrated in (17).
a. It's about to rain.
b. Tom moved about the room
b. It's about time.
d. John talked about Mary.

Restrictions on the distribution of about have been noted before. According to Sauerland and Stateva (2007), about can only combine with numerals and temporal expressions. Note, however, that about can occur with certain gradable adjectives.
a. about full/empty/?certain/?closed/\#invisible/\#pure
b. about \#wet/\#visible

Maximum-standard gradable adjectives (18a) seem more acceptable than minimum-standard gradable adjectives (18b), but not all maximum-standard gradable adjectives acceptable with about.

I propose that certain gradable adjectives can appear with a conventionalized null-just form of just about. One piece of evidence for this is shown in (19), where true bare about in patterns differently from (null-)just about (see Zaroukian (to appear) for further discussion).
a. about ten $\not \rightarrow$ not ten
b. just about ten $\rightarrow$ not ten
c. about full $\rightarrow$ not full
d. just about full $\rightarrow$ not full

\section{Conclusions}

To summarize, I have proposed that approximately patterns differently with numerals and coercedscalar NPs because approximately (in conjunction with many/much) requires two arguments of type $\langle e t\rangle$, and while the sentence in (1) provides both these arguments (sandwiches and $[\lambda x$.John served $x]$ ), the sentence in (3) only provides one ( $[\lambda x$.John served $x])$. This two-argument requirement, however, is not present in copular sentences like (2) and (4), so both are acceptable. Approximately and about pattern the same with numerals but differently with coerced-scalar NPs because approximately can coerce scalar readings out of non scalars, but about cannot.

\section{References}

Hackl, Martin. 2000. Comparative quantifiers. Doctoral Dissertation, Massachusetts Institute of Technology. Partee, Barbara H. 2008. Noun phrase interpretation and type-shifting principles. In Formal Semantics: The Essential Readings, ed. Paul Portner and Barbara H. Partee. Blackwell Publishers.

Sauerland, Uli, and Penka Stateva. 2007. Scalar vs. epistemic vagueness: Evidence from approximators. In Proceedings of SALT 17, 228-245. Ithaca, NY: CLC Publications, Cornell University.

Zaroukian, Erin. to appear. Gradable predicates and the distribution of approximators. In Proceedings of the Western Conference on Linguistics. California State University at Fresno. 